\title{
Affective Effect: Issue Engagement on a Youth E-Participation Platform
}

\section{Thomas J. Lampoltshammer, Qinfeng Zhu, Peter Parycek}

Department for E-Governance and Administration, Danube University Krems

\{thomas.lampoltshammer, peter.parycek\}@donau-uni.ac.at

Research Centre for Media and Journalism Studies, University of Groningen qinfeng.zhu@rug.nl

Abstract: While E-participation promotes citizen participation in democratic decision-making processes, and often takes place through deliberation, citizens are expected to be cool-headed individuals equipped with reason and logic, insulating their actions from the impulse of emotion. However, research in neuroscience and cognitive science has found that emotion plays a vital part in cognitive processing and is instrumental in decision-making. This study thus fills this research gap by examining the effect of emotions in eliciting participation on a youth E-participation platform. Following affective intelligence theory and appraisal theory, the authors specifically examined three types of emotions; namely, anger, anxiety, and sadness. By applying methods in the field of text and statistical analysis, the authors found that anxiety, although the least common type of emotion expressed on the E-participation platform, was associated with an increased level of engagement. On the contrary, anger dominated issue discussion across topics, and sadness prevailed in the discourse on system-level economic issues.

Keywords: E-participation; emotions; ICT; public administration; policymaking

Acknowledgement: The first and second author contributed equally to this paper. The second author's work in this research project was funded by the Ernst Mach Grant-Eurasia-Pacific Uninet, financed by the Austrian Federal Ministry of Education, Science and Research (BMBWF).

\section{Introduction}

Participation, known as actions, aimed at influencing formal political institutions and their decisionmaking (Verba, Schlozman, \& Brady, 1995), requires mobilisation of cognitive resources and action. Emotions countering conventional views, are complex patterns of cognitive processes, physiological arousal, and behavioural reactions (Kleinginna \& Kleinginna, 1981), and hence likely to play an important role in political actions. Existing studies on the effect of emotion on participation have mainly focused on institutional political activities such as voting and campaigning (e.g., Brader, 
2005; Glaser \& Salovey, 1998; Valentino, Brader, Groenendyk, Gregorowicz, \& Hutchings, 2011; Weber, 2013), as well as non-institutional contentious political participation such as protests (e.g., Jasper, 1998). Yet, little is known about the affective effect in government-curated e-participation platforms, where participation primarily takes place in the form of deliberation. This study thus explores the impact of emotions on e-participation. We focus on participation in the form of expressing one's opinion and preference, through commenting on public issues. Often studied under the term "deliberation", this form of participation draws on mental articulation and intra-personal reasoning and aims to produce reasonable, well-informed opinions (Carpini, Cook, \& Jacobs, 2004). Specifically, we focus on three discrete emotions that are rife in the current political discourse, namely anxiety, anger, and sadness. They all share a negative emotional valence that, according to appraisal theories of emotion, arises from the perception that an individual's goal and the environment share an incongruent relationship (Dillard \& Shen, 2007). However, they operate as distinct systems for processing information and mobilizing psychological and physiological resources, and thus predispose individuals to act in specific ways (Dillard \& Shen, 2007; Lerner \& Keltner, 2001; Russell, 2003). We thus seek answers to the questions of how these discrete emotions affect e-participation; specifically, (1) how the three types of emotions distribute across issue topics, and (2) how the emotional dimensions of issues predict the level of deliberative participation.

\section{Emotions and Participation}

While rationality and reasoning are often hailed as the central pillar of deliberation (Carpini et al., 2004), emotion is conventionally viewed as something inferior, which puts sound decision-making in jeopardy. However, in fact, emotion is inevitable, and moreover, a vital part of human cognition and decision-making. First of all, affective response arises from the somatic and automatic nervous system, occurring largely outside of conscious awareness (Gruszczynski, Balzer, Jacobs, Smith, \& Hibbing, 2013; Russell, 2003). Although logical decision-making that relies on rational method and follows the principle of utility, seems theoretically feasible, in reality, "gut feelings" often come first and tilts the direction of further reasoning that serves to justify our intuitive inclinations (Haidt, 2012). As Hume's (1978) dictum goes, reason is the "slave of passions" and "a gun for hire". In other words, it is difficult for individuals to be fully aware of their emotional state and of the influence it sheds on their judgment and action, and to eschew their basic emotional predispositions. Moreover, emotion is not opposite to cognition; rather, it acts as an indispensable information processor and functions as an aid to bounded rationality (Hanoch, 2002; Spezio \& Adolphs, 2007). Research in neuroscience shows that, without the input from a functioning limbic system, aka the emotion centre of the brain, a person's ability to make good decisions, listing the pros and cons, and then act upon them is seriously impaired, arguably because emotional values of future outcomes are missing from the equation (Damasio \& Damasio, 1994). According to appraisal theory, emotion prepares individuals to selectively attend to, encode, and retrieve affect-congruent information (Lerner \& Keltner, 2001; Russell, 2003). By creating such mental "shortcuts", it guides individuals through the labyrinth of an information-saturated, complex world with their limited computational abilities (Hanoch, 2002). Furthermore, as a result of adaptive revolution, emotion, experienced as physiological arousal, mobilizes individuals to act, or inhibits them from acting (Berger \& Milkman, 2012; Russell, 2003). The importance of understanding how emotion plays out in participation is thus self-evident. 


\subsection{Anxiety}

Anxiety is "a unique and coherent cognitive-affective structure within our defensive motivational system", characterised by "a state of helplessness, because of a perceived inability to predict, control, or obtain desired results or outcomes in certain upcoming personally salient situations or contexts" (Barlow, 2000, p.1249). In a series of experiments, Lerner and Keltner (Lerner \& Keltner, 2001) observed that, when anxiety was induced, individuals estimated future events as unpredictable and uncertain, and perceived little personal control over them. Recent neuroscience research has discovered that this sense of uncontrollability and helplessness is nevertheless accompanied by a strong physiological or somatic component; certain brain circuits are activated to prepare anxious individuals to counteract helplessness and to deal with potentially negative events, inducing a state of vigilance (Barlow, 2000). As propounded in affective intelligence theory, anxiety triggers the "surveillance system"; characterised by enhanced cognitive function, anxious individuals are likely to scrutinise the environment vigilantly and attend to new information (Marcus et al., 2000). Empirical studies in political psychology have also shown that, in novel situations, anxiety leads citizens to actively acquire knowledge, rely more on substantive information such as issue positions than heuristics such as partisan cues, and seek common ground and compromise (Brader, 2005; Gruszczynski et al., 2013; Marcus et al., 2000; Valentino, Hutchings, Banks, \& Davis, 2008). In short, anxiety can be beneficial to deliberation, in that it produces a more balanced information search and willingness to understand dissenting voices. However, inconsistent findings also exist. For example, Ladd and Lenz (Ladd \& Lenz, 2008) show that evaluation of political candidates drives anxiety, rather than vice versa. Given that the result is derived from cross-sectional self-reported survey data, it may reflect long-term dispositional anxiety rather than temporarily induced anxious states. Although in many real-world conditions, long-term dispositional anxiety, especially at a high level, may interfere with learning, a positive correlation has been consistently observed when an anxious state is temporarily induced (Valentino et al., 2008). In the environment of e-participation, expression of anxiety may, to a certain extent, reflect an individual's core affect. However, it is also likely to be induced by the issues being discussed, subject to the nature of an issue, and the general social and political discourse around it. Furthermore, anxiety, at a proportional level, is a high-arousal emotion that predisposes individuals to take actions. For example, anxiety-inducing stories are likely to be emailed and go viral (Berger \& Milkman, 2012). In a sense, sharing anxiety-inducing stories can perhaps be seen as a collective act to publicise and amplify the future threat or danger, and to mobilise others to counteract the potentially negative outcomes. This is also consistent with findings drawn upon the spiral of silence theory that, fear of undesirable future outcomes, particularly social anxiety, such as rejection and sanction can impose conformity (Moy, Domke, \& Stamm, 2001; NoelleNeumann, 1974, 1979). In other words, when participation begins to be perceived as the norm, individuals are likely to conform. To summarize, anxiety, particularly temporarily induced anxiety, functions as a psychological mechanism underlying information seeking and learning, and activates the desire in individuals to reduce uncertainty, regain control, and conform. We thus propose the following hypotheses:

H1. Anxiety is positively related to deliberative participation. 


\subsection{Anger}

Contrary to anxiety, anger shuts down information processing, leads to a reliance on past attitudes and behaviour, and rejects accommodation (MacKuen, Wolak, Keele, \& Marcus, 2010). In other words, when engulfed by the feeling of anger, tolerance for dissenting voices declines and the "fight" brain response is activated. Anger may thus arouse individuals to participate in competitive and contentious politics such as casting votes and joining protests (Gruszczynski et al., 2013; Ladd \& Lenz, 2008; Weber, 2013). However, it may inhibit individuals from hearing the other side, as engaging with disagreement requires a "cool head". Gruszczynski and colleagues (Gruszczynski et al., 2013) find that increases in electrodermal responsiveness, a common measure of individuals' affective physiological response, are not associated with persuasion or articulation of issue positions. Besides, emotions are not only functional as a product of Darwinian evolution, but also normative as a social construct. We can assume that on a government-curated e-participation platform, where deliberation is encouraged and civility the norm, an excessive display of anger may be perceived as undesirable. In addition, posting messages fuelled by anger runs the risk of being removed by the moderators on the e-participation platform. Given the deliberative nature of the E-participation platform, we propose that:

H2. Anger is negatively related to deliberative participation.

\subsection{Sadness}

Different from anxiety or anger, sadness is characterized by low arousal (Feldman Barrett \& Russell, 1998). Arousal refers to "a state of the central nervous system experienced as a subjective feeling and with peripheral correlates" (Russell, 2003, p.154). It is a physiological process, manifested as autonomic activities such as skin conductance, heat rate, or blood pressure, and functioning as a "motor activation" that determines individuals' actions in relation to the environment (e.g., approach, avoid, neither) (Heilman, 1997). While high-arousal emotions mobilize individuals in preparation for vigorous action, low-arousal emotions deactivate. Studies show that sadness-inducing stories are less viral than anxiety- or anger- inducing stories, and that the negative relationship between sadness and content transmission strengthens with increasing emotion intensity (Berger \& Milkman, 2012). Individuals with low electrodermal responsiveness (an indicator of arousal) tend to shy away from the political arena (Gruszczynski et al., 2013). Besides, expressions of sadness may interfere with how one's arguments and opinions are received. For example, a series of experimental studies have revealed that people confer status on politicians who express anger rather than sadness, and that expressions of sadness are not related to the perception of the person's competence (Tiedens, 2001). By the same token, messages fused with sadness may not only inhibit individuals' reactions at a physiological level but may also be a sign of incompetence at a cognitive level. We thus propose the following hypotheses:

H3. Sadness is negatively related to deliberative participation. 


\subsection{Emotions across topics}

As situations and judgment moderate emotion dimensions (Lerner \& Keltner, 2001), the expression of emotions may vary across discussions on different topics. This study thus further considers how different topics are expressed with the three types of emotions. Results so far are mixed regarding the relationship between topics and emotions. Some studies have shown that discussing controversial topics may induce feelings of threat, social ambivalence, and anxiety (Mutz, 2002; Nir, 2005; Simons \& Green, 2018). Other scholars, however, find that discussion of value-laden, polarising issues is likely to trigger defence motives and move expressors to a fortified version of their views (Matthes, Rios Morrison, \& Schemer, 2010). Such discussions may hence be accompanied by anger instead of anxiety. Relevant to issue discussions, existing research shows that different citizenship practices are associated with different emotions. Citizenship practised as collective pursuit of a common good is guided by a Tocquevillian sense of citizenship duty and hence more inclusive (Campbell, 2006). It is often associated with anxiety that enhances cognitive function and encourages a balanced information search and willingness to compromise (MacKuen et al., 2010). In contrast, dictated by a Madisonian impulse towards factionalism, citizenship practised as partisan combat is inherently tribal (Campbell, 2006; Haidt, 2012). It provokes anger and aversion that shuts down information processing and activates selective attention (MacKuen et al., 2010). This line of research suggests that discussion about issues concerning politic,s is likely to contain strong a emotion of anger, whereas discussion about civic issues is likely to be associated with anxiety. However, topics are always discussed within specific socio-political contexts. It may be arbitrary to claim that discussion about employment, for instance, is less divisive than that about elections. To understand how various topics are expressed with emotions, we put forward the two following research questions:

RQ1: What are the topics being discussed on the e-participation platform?

RQ2: How are the emotions of anxiety, anger, and sadness distributed across the topics?

\section{Emotions and Participation}

\subsection{E-Participation platform OurSpace}

This study used the youth e-participation platform OurSpace as the research case. OurSpace is an online deliberation platform delivered as part of a multi-national e-participation project launched in July 2010 and co-funded by the European Commission under the ICT Policy Support Programme. It was designed to engage young European citizens in a discussion of EU affairs, at both at national and supranational level, with the aim of bringing European politics and decision makers closer to European youth and involving them in the decision-making process. Between 1 September 2012 and 31 December 2014, the project was piloted in four European countries, namely Austria, the Czech Republic, Greece, and the United Kingdom. This study tested the hypotheses using the computational data generated on OurSpace platform during the pilot phase. The data was generated in a semi-natural setting in that during the early stage of the pilots, the project partners actively promoted the platform, mobilised interest, and encouraged participation through a series of events and 
social media campaigns, workshops, and collaboration with youth organizations and schools. Different promotion strategies were employed in the four pilot countries. While the pilots in the Czech Republic, Greece, and the UK leveraged the existing network resources of youth organizations, the Austrian pilot operated largely through school events and workshops. Since the level of participation on the platform is partially a result of official promotion, one may need to exercise caution when generalizing the findings beyond this e-participation initiative. On the other hand, we can also perhaps see these official promotion efforts as a means to "seed" the initial adoption of the new practice (i.e., participation), which is often crucial in setting off the diffusion process in real-world events.

\subsection{Data}

The dataset for this study consists of data from June 2011 to September 2016, containing altogether about 4,900 unique user posts. The data were directly exported from the OurSpace database into an Excel-based format for further processing. The following dimensions of the data were used for the analysis for this study: the unique ID of a post, the subject of the post, the body (actual content) of the post, and the language the post was created in. The languages found in the data are English, German, Greek, and Czech. In order to be able to analyse inherent topics and associated emotions within the data, a common denominator in terms of a language had to be selected. The authors selected the English language to be used for further processing and analysis in this study, as the original dictionaries available for LIWC2015 do not cover Greek and Czech. Therefore, this necessitated the translation of the remaining posts, which had not been written in English. To provide a consistent level of translation quality in an automated way, the authors chose to use the Google Translation API for this purpose. Using automated translation processes may have potential shortcomings in terms of translation accuracy, depending on the data themselves as well as the intended field of application. In general, previous studies have demonstrated that automated translation technologies have already reached a level of sophistication that allows for their use in academia (e.g., (Groves \& Mundt, 2015). Yet, the overall accuracy of the actual translation strongly depends of the domain of the text as well as on the combination of the source and target language (Chen, Acosta, \& Barry, 2016). While machine translations can have an impact on the sentiment of a given text, depending on the feature selection (Li, Graesser, \& Cai, 2014), machine translation has reached a level of accuracy sufficient enough to be applied to multilanguage sentiment analysis (Balahur \& Turchi, 2014), In addition, the analysis conducted on the OurSpace data is based on word level and not on sentence level (due to the way LIWC2015 corpus analysis works; see Pennebaker, Boyd, Jordan \& Blackburn, 2015), which significantly reduces the potential negative impact of grammar errors in the results.

\subsection{Measurements}

\subsubsection{Emotions}

This study uses Linguistic Inquiry and Word Count (LIWC2015) to analyse the corpus for various linguistic traits, in particular the emotional components of the text samples. LIWC is an established text analysis program for measuring verbal expression of emotions (Kahn, Tobin, Massey, \& Anderson, 2007). It is based on the research findings that the function and emotion words people use, 
reveal important psychological cues to their emotional states, thought processes, and individual differences, among other things. The program identifies psychological cues through placing words from a text file into categories based on a psychometrically validated internal dictionary, and then calculating the percentage of words in each LIWC category (Tausczik \& Pennebaker, 2010). For our measurement of emotions, we used the LIWC category "affective processes" that consists of "positive emotions", "negative emotions", "anxiety", "anger", and "sadness". The LIWC dictionary contains 1393 emotionally relevant words in total. For information of each sub-category please see Table 1. The analysis yielded a score for each affective sub-category, with anger scoring a mean value of .46 (S.D.= .93), sadness .25 (S.D.= .54), and anxiety .23 (S.D.= .53).

Table 1: LIWC2015 "affective processes" category output variable information.

\begin{tabular}{|c|c|c|c|c|}
\hline EMOTIONS & EXAMPLES & $\begin{array}{c}\text { WORDS } \\
\text { IN CATEGORY }\end{array}$ & $\begin{array}{l}\text { INTERNAL CON- } \\
\text { SISTENCY (UNCOR- } \\
\text { RECTED APHA) }\end{array}$ & $\begin{array}{l}\text { INTERNAL CON- } \\
\text { SISTENCY (COR- } \\
\text { RECTED ALPHA) }\end{array}$ \\
\hline $\begin{array}{l}\text { POSITIVE } \\
\text { EMOTIONS }\end{array}$ & $\begin{array}{l}\text { love, nice, } \\
\text { sweet }\end{array}$ & 620 & .23 & .64 \\
\hline $\begin{array}{l}\text { NEGATIVE } \\
\text { EMOTIONS }\end{array}$ & $\begin{array}{l}\text { hurt, ugly, } \\
\text { nasty }\end{array}$ & 744 & .17 & .55 \\
\hline SADNESS & $\begin{array}{l}\text { worried, fear- } \\
\text { ful }\end{array}$ & 116 & .31 & .73 \\
\hline ANXIETY & $\begin{array}{l}\text { hate, kill, an- } \\
\text { noyed }\end{array}$ & 230 & .16 & .53 \\
\hline ANGER & $\begin{array}{l}\text { crying, grief, } \\
\text { sad }\end{array}$ & 136 & .28 & .70 \\
\hline
\end{tabular}

\subsubsection{Topics}

The topic modelling process was conducted via the KNIME Analytics Platform, which allows for the construction of the required pre-processing of the data to render it suitable for the topic modelling process. In the first step, the data were loaded into the KNIME workflow by translating them from the Excel-based file format into the internal String-Document representation of KNIME. Afterwards, the internal stop-word (Fox, 1989) filter of KNIME was applied to remove all unnecessary words from the text corpus. In the next step, all punctuation and numbers (in numeric format) were removed. Once this process was complete, the Kuhlen stemmer algorithm (Kuhlen, 1977) was applied to the corpus in order to have all words reduced to their original stem form. Then, all words with a character count of less than three were removed. Finally, all words were transformed to lower-case notation. The resulting text corpus was fed into the topic extractor module of KNIME, based on a parallelized version of the Latent Dirichlet Allocation (LDA) algorithm (Newman, Asuncion, Smyth, \& Welling, 2009; Yao, Mimno, \& McCallum, 2009). The LDA can be described as “[...] a 
generative probabilistic model of a corpus. The basic idea is that documents are represented as random mixtures over latent topics, where each topic is characterized by a distribution over words" (Blei, $\mathrm{Ng}$, \& Jordan, 2003, p.996). After multiple runs to identify the suitable number of topics, the authors selected a combination of 10 topics with 10 words each, for the sake of the modelling process in this study.

\subsubsection{Participation}

We measured the level of participation as the number of comments in reply to an initial post (M= 5.16, S.D. $=10.98$ ). For the statistical analysi,s to test the hypotheses, we conducted a series of OLS regressions with the level of participation as the dependent variable, and anxiety, anger, and sadness as independent variables. We also controlled for the valence of emotion (i.e., positive or negative), word count, cognitive capacity, and language used in each initial post in the regressions. The unit of analysis is each thread, composed of one initial post and following comments. The statistical analysis tool SPSS 20.0.0 was employed for the analysis.

\section{Results}

\subsection{Descriptive Results}

The sample contains 615 threads, with each thread composed of one initial post and a series of comments. In total, 3173 comments were submitted in reply to 615 initial posts $(M=5.16$, S.D. $=10.98)$. Overall, positive emotions $(\mathrm{M}=2.56$, S.D.= 2.31) prevailed over negative emotions $(\mathrm{M}=1.63, \mathrm{~S} . \mathrm{D} .=$ 2.04). In terms of specific emotion, anger is the most prevalent $(M=.46$, S.D. $=.93)$, followed by sadness $(\mathrm{M}=.25$, S.D. $=.54)$ and anxiety $(\mathrm{M}=.23$, S.D. $=.53)$ (see Table 2$)$.

The sample consists of messages written in four languages, i.e., English, Greek, German, and Czech, with the Greek-speaking community being the most active in initiating discussions (i.e., number of initial posts) $(\mathrm{N}=204)$, followed by the Czech $(\mathrm{N}=171)$, English $(\mathrm{N}=165)$, and German $(\mathrm{N}=$ 75). A one-way ANOVA test also shows significant between-group difference in the level of participation (i.e., number of comments) $(\mathrm{F}(3,611)=6.25, \mathrm{p}<.001)$. Specifically, the Greek-speaking community is the most engaged, with an average number of comments of 6.91 (S.D. $=15.66$ ), followed by the Czech community $(M=6.31$, S.D.= 9.36). Posts written in German ( $M=3.69$, S.D. $=6.31)$ and English $(M=2.47$, S.D. $=5.04)$ received significantly fewer comments on average.

However, emotions are distributed relatively evenly across the four language groups. One-way ANOVA tests yield no significant between-group differences in negative emotions $(\mathrm{F}(3,611)=1.93$, $\mathrm{p}=.124)$, anger $(\mathrm{F}(3,611)=.12, \mathrm{p}=.950)$, or anxiety $(\mathrm{F}(3,611)=2.38, \mathrm{p}=.069)$. However, the four groups displayed significantly different levels of sadness in their initial posts $(F(3,611)=3.99$, $p<$ $.01)$; posts written in Greek ranked the top on the sadness scale $(\mathrm{M}=.34$, S.D. $=.59)$, followed by the English ( $\mathrm{M}=.26$, S.D.= .57), German $(\mathrm{M}=.17$, S.D. $=.40)$, and Czech $(\mathrm{M}=.16$, S.D.= .48). Positive emotion also varied significantly across groups $(\mathrm{F}(3,611)=3.11, \mathrm{p}<.05)$, with English posts being the most positive $(M=2.93$, S.D.= 2.75), followed by Czech $(M=2.67$, S.D. $=2.57)$, Greek $(M=2.28$, S.D. $=1.81)$, and German $(\mathrm{M}=2.22$, S.D. $=1.70)$. 
Table 2: Descriptive statistics.

\begin{tabular}{l|ccccc} 
VARIABLES & $\mathbf{N}$ & MIN & MAX & M & S.D. \\
\hline $\begin{array}{l}\text { DELIBERATIVE } \\
\text { PARTICIPA- } \\
\text { TION }\end{array}$ & 615 & 0 & 142 & 5.16 & \\
& & & & \\
POSITIVE \\
EMOTION
\end{tabular}

\subsection{Emotions and Participation}

To test the hypotheses, we conducted an OLS regression with the level of participation (i.e., number of comments an initial post has received) as the outcome and anxiety, anger, and sadness expressed in the initial posts as the predictors, while controlling for the valence of emotion (i.e., positive or negative), word count, cognitive capacity, and language used in each initial post. Since anxiety, anger, and sadness share certain degrees of negative valence, Pearson's correlation showed that they were substantially and significantly correlated with negative emotion (Table 3), suggesting a potential multicollinearity issue. We thus estimated the "tolerance" value for each predictor. The analysis yielded tolerance values all above .10, suggesting that no serious multicollinearity was present. 
Table 3: Zero-order correlations (two-tailed Pearson's r).

\begin{tabular}{l|ccccccc}
\multicolumn{1}{l}{} & NEG. & ANXIETY & ANGER & SANESS & $\begin{array}{l}\text { WORD } \\
\text { COUNT }\end{array}$ & $\begin{array}{l}\text { COG. } \\
\text { PROC. }\end{array}$ & $\begin{array}{l}\text { COM- } \\
\text { MENTS }\end{array}$ \\
\hline $\begin{array}{l}\text { POSITIVE } \\
\text { EMOTION }\end{array}$ & -.06 & -.03 & $-.08^{*}$ & -.01 & -.01 & $.08^{*}$ & -.02 \\
NEGATIVE & - & $.40^{* * *}$ & $.63^{* * *}$ & $.38^{* * *}$ & .04 & $.09^{*}$ & -.03 \\
EMOTION & & & & & & & \\
\\
ANXIETY
\end{tabular}

Note: ${ }^{*} p<.05,{ }^{* *} p<.01,{ }^{* *} p<.001, \# p=.057$

As shown in Table 4, among the three types of emotions, only anxiety expressed in an initial post is positively and significantly correlated with the level of participation the initial post has elicited, although the magnitude of the effect is rather small $(\beta=.11, p<.05)$. H1 is thus supported. Anger and sadness are both negatively correlated with participation, but without statistical significance $(\beta$ $=-.03, \mathrm{p}=.56 ; \beta=-.02, \mathrm{p}=.78$ ). $\mathrm{H} 2$ and $\mathrm{H} 3$ are thus rejected. Valence of emotion (i.e., positive or negative emotions) displayed in an initial post does not predict the number of comments it will elicit. 
Table 4: Summary of OLS regression predicting participation.

\begin{tabular}{|c|c|c|c|}
\hline PREDICTORS & B (S.D.) & BETA & TOLERANCE \\
\hline POSITIVE EMOTION & $-.05(.19)$ & -.01 & .97 \\
\hline NEGATIVE EMOTION & $-.33(.32)$ & -.06 & .44 \\
\hline ANXIETY & $2.34(.91)^{*}$ & $.11^{*}$ & .82 \\
\hline ANGER & $-.32(.63)$ & -.03 & .56 \\
\hline SADNESS & $-.31(.92)$ & -.02 & .78 \\
\hline WORD COUNT & $.00(00)$ & .05 & .95 \\
\hline COGNITIVE PROCESS & $.14(.08)$ & .07 & .94 \\
\hline GREEK $^{* * *}$ & $2.02(.73)^{\star *}$ & $.14^{* *}$ & .61 \\
\hline GERMAN*** $^{* *}$ & $-1.11(1.01)$ & -.06 & .50 \\
\hline $\mathrm{CZECH}^{* * *}$ & $1.55(.77)^{*}$ & $.10^{*}$ & .59 \\
\hline CONSTANT & $3.07(1.28)^{*}$ & - & - \\
\hline ADJUST R2 & - & .03 & - \\
\hline$F(D F)$ & - & $3.00(10)^{* *}$ & - \\
\hline$N$ & - & 615 & - \\
\hline
\end{tabular}

Note: B unstandardised regression coefficient; Beta standardized coefficient ${ }^{*} p<.05,{ }^{* *} p<.01,{ }^{* * *}$ reference group: English 


\subsection{Topics, Emotions, and Participation}

Topics: Topic modelling analysis resulted in 10 topics covering issues ranging from (1) crime and security, (2) health and environment, (3) jobs and livelihoods, (4) unemployment and welfare, (5) education and youth development, (6) immigration and integration, (7) economic system, (8) institutional politics, (9) non-institutional politics, to (10) international affairs. To understand the substance of the generated topics and to examine the validity of the topic model, we followed up the topic modelling with a manual open coding, that revealed sub-topics of each generated topic, as listed in Table 5.

Table 5: Summary of generated topics.

Topics

Crime and security
Terms

Crime, data, law, public, criminal, drug, increase, citizen, information, action
Health, environment Smoke, environmental, human, and other social issues

Jobs and livelihoods

employment welfare

and People, European, youth, Eu-

Education and youth School, education, student, development rope, country, unemployment, help, government, union, social

pollution, network, social main, air, effect, plant

Job, country, live, month, play, people, money, Belgium, EUR, government

children, university, teacher, opinion, system, study, learn

\section{Immigration and integration}

Economic system
Service, immigrant, military, immigration, integration, African, sport, Austria, marriage, west

Greece, Greek, country, bank, German, tax, money, loan, Germany, Euro
Sub-topics

Crimes, legalisation of cannabis, drug abuse, privacy and data protection, government open data, animal abuse, game violence, etc.

Smoking and alcohol, food, euthanasia, suicide, environmental issues, nuclear power, etc.

Jobs, work condition, poverty, shop opening hours, public transportation, etc.

Unemployment, food stamps, minimum wage, gender pay gap, disability, community involvement, innovation, etc.

Education system, tuition fees, problematic behaviour in school (e.g., bullying, racial discrimination, etc.), child protection (e.g., adoption, child abuse), youth health, voting age, etc.

Refugee and immigration crisis, far right groups, racial and religious discrimination, minority groups (e.g., LGBT, Muslims), crime, military service, etc.

Financial crisis, tax and taxation, bank, insurance, tourism, etc. 


\section{Institutional politics}

\author{
Non-institutional \\ politics
}

Party, election, vote, democracy, Czech, political people, citizen, republic, parliament

Greek, protest, society, country, dawn, movement, political, golden, change, Greece
Democracy, elections, voting, political parties, politicians, corruption, parliament, etc.

Political protests, social movements, political change, patriotism and nationalism, far right/left politics, corruption, etc.

International relations and politics(e.g., China threat, China Tibet, Russia in Ukraine, Turkey joining EU, US-EU relationship, etc.), Islam in Europe, space mission, etc.

Notes: a Results of topic modeling b Sequence of terms following descending weight c Results of manual open coding of each post

Descriptive analysis shows that, first of all, topics highly relevant to young people, such as unemployment $(\mathrm{N}=140,22.8 \%)$ and education $(\mathrm{N}=95,15.4 \%)$ are among the most discussed topics. Politics, including institutional politics $(\mathrm{N}=98,15.9 \%)$, non-institutional politics $(\mathrm{N}=50,8.1 \%)$, and international affairs $(\mathrm{N}=55,8.9 \%)$, also attracted a fair amount of attention. Interestingly, topics concerning people's daily lives such as health and environment $(\mathrm{N}=41,6.7 \%)$, crime and security $(\mathrm{N}=$ $33,5.4 \%)$, and jobs and livelihoods ( $\mathrm{N}=28,4.6 \%)$ scored low on the popularity scale. Additionally, although highly contested in Europe's public arena, economic performance (N=40,6.5\%) and immigration issues $(\mathrm{N}=35,5.7 \%)$ received relatively little attention on the e-participation platform. In terms of participation (number of comments to each initial post), the distribution of participation across the topics (Fig 2) does not align perfectly with the distribution of initial posts (Fig 1). Unemployment and welfare, the most popular topic among the initial posts, only received a below-average number of comments $(\mathrm{M}=3.81$, S.D. = 7.29). On the contrary, the topic of immigration and integration, although only discussed in a small number of posts, elicited the highest level of participation on average $(M=10.86$, S.D. $=25.19)$. 
Figure 1: Number of posts across topics.

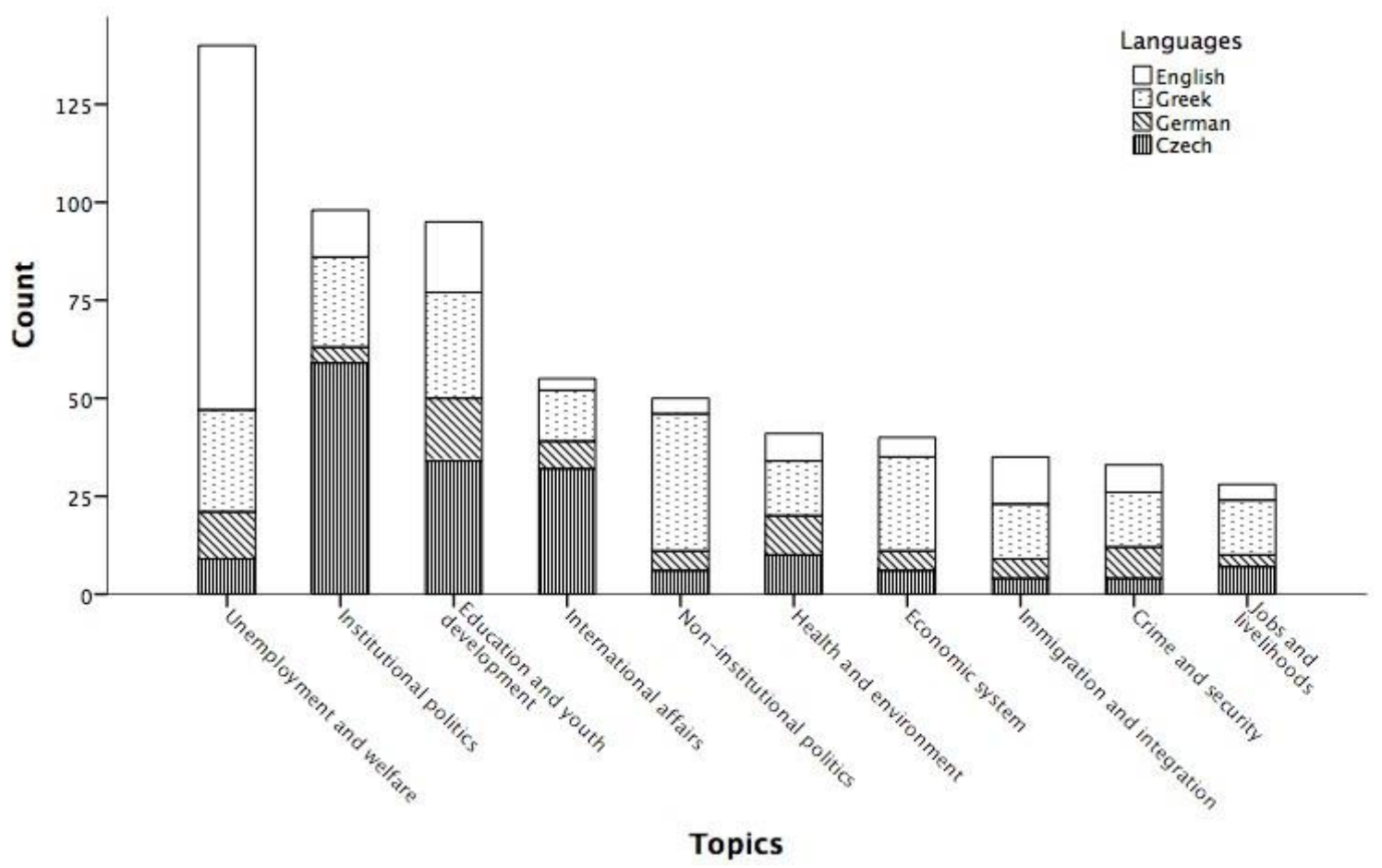

Well covered in initial posts, topics on education and youth development (M= 7.49, S.D. = 10.65), and politics including non-institutional politics $(M=7.5$, S.D. $=15.04)$ and institutional politics $(M=$ 6.2, S.D. $=9.14)$, also received relatively high numbers of comments. However, posts on international affairs are met with a relatively low-level participation rate $(M=3.44$, S.D. $=12.08)$. Topics concerning people's daily lives continue to receive only a few comments, including crime and security (M= 3.73, S.D. = 6.11), jobs and livelihoods (M=3.61, S.D. = 7.82), and health and environment $(M=2$, S.D. $=3.94)$. The same is true of economic issues $(\mathrm{M}=1.72$, S.D. $=3.19)$.

One-way ANOVA tests further yielded significant between-topic difference in the number of comments $(F(9,605)=3.31, p<.01)$. Specifically, a post hoc Turkey test showed that posts on the topic of immigration and integration $(M=10.86$, S.D. $=25.19)$ received significantly more comments than posts pertaining to economic issues $(\mathrm{M}=1.72$, S.D. $=3.19, \mathrm{p}<.05)$, international affairs $(\mathrm{M}=3.44$, S.D. $=12.08, \mathrm{p}=.05)$, and unemployment and welfare $(\mathrm{M}=3.81$, S.D. $=7.29, \mathrm{p}<.05)$.

Regarding the distribution of emotions in each topic, anger dominates most of the topics (see Figure 3 and Table 6). In comparison, anxiety and sadness are in general less prevalent. Anxiety is salient only among the posts about unemployment and welfare $(\mathrm{M}=.28$, S.D. $=.64)$, and immigration and integration $(\mathrm{M}=.28$, S.D. $=.52)$. Only in the posts discussing economic issues, does sadness prevail $(\mathrm{M}=.42$, S.D. $=.63)$. In terms of the distribution of anger across topics, posts on non-institutional politics score the highest $(\mathrm{M}=.88$, S.D. $=1.31)$, followed by jobs and livelihoods $(\mathrm{M}=.72$, S.D. $=.98)$, crime and security $(\mathrm{M}=.70$, S.D. $=1.28)$, international affairs $(\mathrm{M}=.67$, S.D. $=.94)$, health and environment $(\mathrm{M}=.55$, S.D. $=.91)$, education and youth development $(\mathrm{M}=.49$, S.D. $=1.19)$, institutional politics $(\mathrm{M}=.33$, S.D. $=.82)$, unemployment and welfare $(\mathrm{M}=.27$, S.D. $=.61)$, immigration and integration $(\mathrm{M}=.26$, S.D. $=.42)$ and economic system $(\mathrm{M}=.21$, S.D. $=.40)$. 
In general, discussions about political issues contain stronger anger responses than the rest,and topics concerning citizens' daily lives are expressed with greater anger than system-level issues.

Furthermore, one-way ANOVA on anxiety $(\mathrm{F}(9,605)=2.36, \mathrm{p}<.05)$, anger $(\mathrm{F}(9,605)=3.44, \mathrm{p}<$ $.001)$, and sadness scores $(F(9,605)=2.07, \mathrm{p}<.05)$ yielded significant variation among the topics respectively. Post hoc Turkey tests showed that posts about non-institutional politics expressed significantly stronger anxiety than those about institutional politics at $\mathrm{p}<.05$. Non-institutional politics also contained significantly stronger anger emotion than institutional politics at $p<.05$, economic system at $p<.05$, and unemployment and welfare at $p<.01$. In terms of sadness, only those posts discussing economic systems scored higher than institutional politics, with a marginal statistical significance $(p=.52)$. The rest of the topics are not significantly different from one another.

Figure 2: Number of comments across topics (mean)

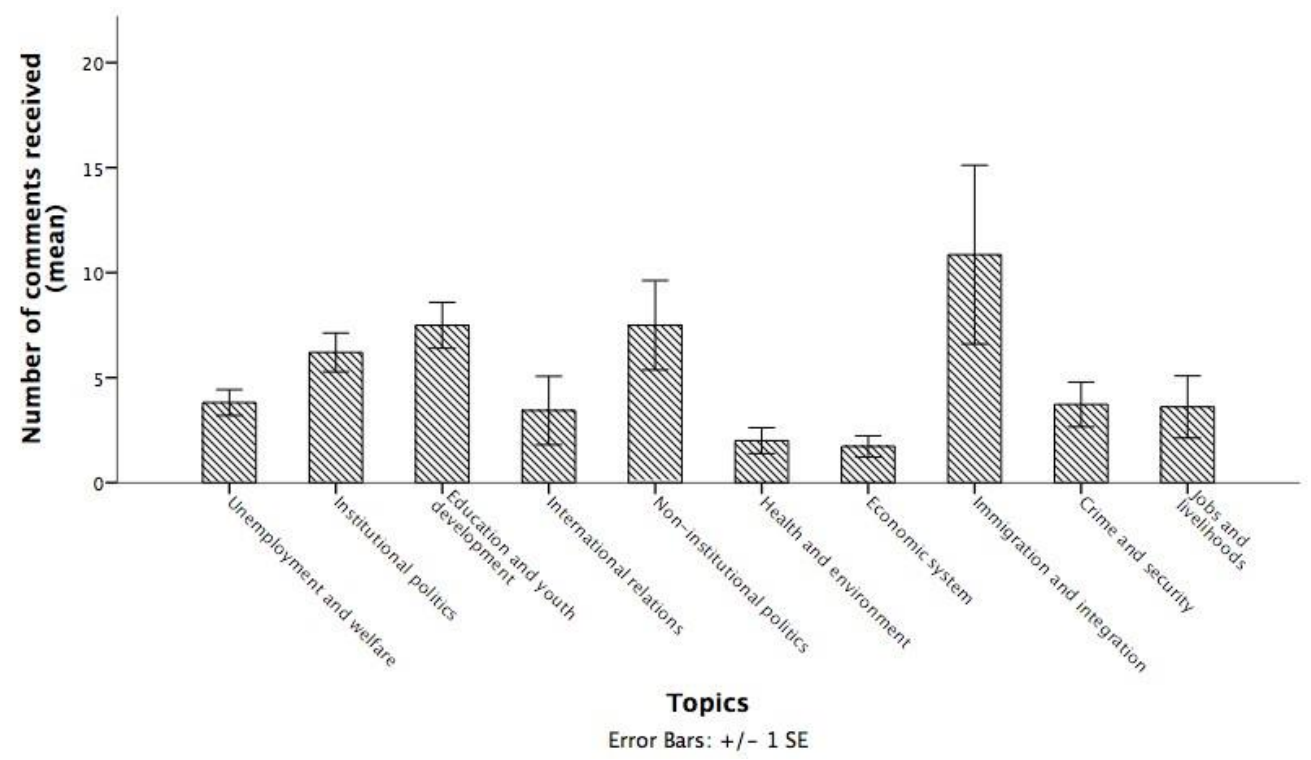

Figure 3: Distribution of anxiety, anger, and sadness scores across topics (mean)

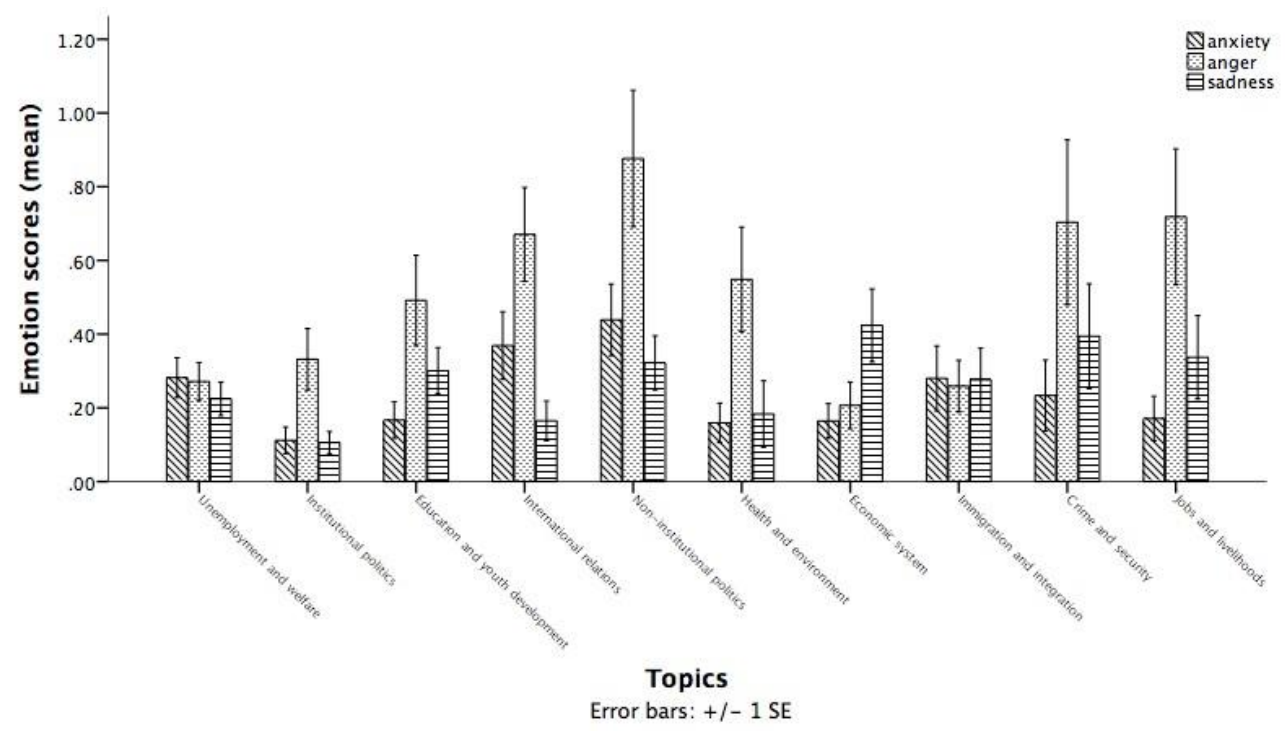


Table: 6 Summary of posts, participation, and emotion across topics.

TOPICS

\begin{tabular}{|c|c|c|c|c|c|}
\hline & $\begin{array}{l}\text { Posts } \\
\text { (N) }\end{array}$ & $\begin{array}{l}\text { Comments } \\
\text { M (S.D.) }\end{array}$ & $\begin{array}{l}\text { Anger } \\
\text { M (S.D.) }\end{array}$ & $\begin{array}{l}\text { Anxiety } \\
\text { M (S.D.) }\end{array}$ & $\begin{array}{l}\text { Sadness } \\
\text { M (S.D.) }\end{array}$ \\
\hline $\begin{array}{l}\text { UNEMPLOYMENT } \\
\text { AND WELFARE }\end{array}$ & 140 & $3.81(7.29)$ & $.27(.61)$ & $.28(.64)$ & $.22(.54)$ \\
\hline $\begin{array}{l}\text { INSTITUTIONAL } \\
\text { POLITICS }\end{array}$ & 98 & $6.20(9.14)$ & $.33(.82)$ & $.11(.36)$ & $.11(.30)$ \\
\hline $\begin{array}{l}\text { EDUCATION AND } \\
\text { YOUTH DEVELOP- } \\
\text { MENT }\end{array}$ & 95 & 7.49 (10.65) & .49 (1.19) & $.17(.48)$ & $.30(.61)$ \\
\hline $\begin{array}{l}\text { INTERNATIONAL } \\
\text { AFFAIRS }\end{array}$ & 55 & $3.44(12.08)$ & $.67(.94)$ & $.37(.68)$ & $.16(.40)$ \\
\hline $\begin{array}{l}\text { NON-INSTITU- } \\
\text { TIONAL POLITICS }\end{array}$ & 50 & $7.50(15.04)$ & $.88(1.31)$ & $.44(.69)$ & $.32(.52)$ \\
\hline $\begin{array}{l}\text { HEALTH AND } \\
\text { ENVIRONMENT }\end{array}$ & 41 & $2.00(3.94)$ & $.55(.91)$ & $.16(.34)$ & $.18(.58)$ \\
\hline ECONOMIC SYSTEM & 40 & $1.72(3.19)$ & $.21(.40)$ & $.16(.30)$ & $.42(.63)$ \\
\hline $\begin{array}{l}\text { IMMIGRATION AND } \\
\text { INTEGRATION }\end{array}$ & 35 & $10.86(25.19)$ & $.26(.42)$ & $.28(.52)$ & $.28(.50)$ \\
\hline $\begin{array}{l}\text { CRIME AND } \\
\text { SECURITY }\end{array}$ & 33 & $3.73(6.11)$ & $.70(1.28)$ & $.23(.55)$ & $.39(.82)$ \\
\hline $\begin{array}{l}\text { JOBS AND } \\
\text { LIVELIHOODS }\end{array}$ & 28 & $3.61(7.82)$ & $.72(.98)$ & $.17(.32)$ & $.34(.60)$ \\
\hline TOTAL & 615 & $5.16(10.98)$ & $.46(.93)$ & $.23(.53)$ & $.24(.54)$ \\
\hline
\end{tabular}

\section{EMOTIONS}

INITIAL PARTICIPATION 


\section{Discussion and Conclusion}

E-Participation enables citizens to take part in democratic decision-making proecsses. In this context, during the design of such processes, it is assumed that citizens act and react in a reasonable and logical way and are not being led primarily by their emotions. However, existing research shows that emotion is inevitable and vital to the cognitive process and instrumental in decision-making. This contradiction was addressed by the paper in hand via studying the effect of emotions in eliciting participation on a youth e-participation platform. Following affective intelligence theory and appraisal theory (Lerner \& Keltner, 2000; Marcus et al., 2000), this study specifically examines three types of emotions, namely anger, anxiety, and sadness. They share a negative emotional valence but operate as distinct systems of information processing and physiological arousal. The textual and log data obtained from the e-participation platform allows us to perform text analysis to investigate the levels of the three types of emotions expressed in the written posts, to carry out topic modelling to identify the distribution of the emotions across discussion topics, and to conduct statistical analysis to estimate their relationships with the level of participation.

Consistent with our hypotheses, our findings show that the level of anxiety expressed in the written posts contributes to a high level of follow-up discussions when other content-wise factors are held level, suggesting that the expression of anxiety can facilitate deliberative participation. It supports the existing finding that anxiety triggers the "surveillance system" wherein individuals vigilantly monitor and assess the situation and get prepared to deal with upcoming negative events (Barlow, 2000; Marcus et al., 2000). Moreover, although it is beyond the scope of this study, the findings may have implications in the quality of participation. According to the existing literature on anxiety, it encourages a balanced information search and makes individuals more attuned to novel information and perspectives (MacKuen et al., 2010). It indicates that a certain amount of anxiety can be beneficial to deliberation, and a healthy participation in which reason and tolerance could prevail.

Future research could focus on the quality of participation, instead of mere quantity, and further assess the merit of anxiety in bringing about well-informed and healthy participation. Despite the aforementioned benefit of anxiety, we find that discussion on the e-participation platform scores low in anxiety in general and that, instead, anger is the most prevalent emotion. According to the existing literature on anger, it obstructs information processing, promotes selective attention, and reinforces individuals' predispositions (MacKuen et al., 2010; Marcus et al., 2000). We find the relationship between anger expressed in the initial posts and the level of participation to be negative, although without statistical significance. It suggests that, at least, anger does not contribute to participation, if not inhibiting it. Our topic modelling analysis further suggests that anger dominates most of the topics. Consistent with existing findings (MacKuen et al., 2010; Haidt, 2012), discussions on politics that are inherently tribal are fused with anger. Surprisingly, issues concerning citizens' daily lives, such as crime and security, jobs and livelihoods, environment and health, as well as education, are also expressed with great anger. One potential explanation is that these issues are associated with high-level grievances and hence politicised or even moralised. Politicising issues can trigger aversion directly leading to the decline of participation (MacKuen et al., 2010). Moralising issues can reinforce attitude certainty and commitment and segregate people holding different 
views into isolated groups (Matthes et al., 2010; Ryan, 2017). With the presence of strong aversion and unwillingness to compromise, participation that pursues common ground will certainly suffer and deliberation will break down.

Future studies could further investigate how the issues are framed and presented and whether this relates tothe prevalence of anger. In addition, our findings also show that sadness, although characteristic of low arousal and often an undesirable social trait according to existing literature, does not affect participation in the discussion of public issues on the e-participation platform. Specifically, counter to our hypothesis, we did not find statistical significance in the negative relationship between sadness and participation. In terms of the distribution of sadness across topics, economic issues at a system level, such as financial crisis and austerity measures, are the sole topic in which discussion is overwhelmed by sadness, indicating a high level of inefficacy.

The limitations of this study are as follows. First, the analysis did not take into consideration the roles the piloting organizations played in promoting the e-participation platform, recruiting participants, and encouraging participation. Future research could tackle the issue by using a consistent promotion and recruitment strategy or documenting the different strategies so that the organisationlevel factor can be held even. Second, we only identified the topics being discussed but did not examine how they are discussed. For instance, discussion about public infrastructure can focus on the utility or partisan aspect,hence it is arbitrary to claim anything about the nature of a discussion merely based on the topic. This limitation may also explain why we find emotion and participation to be relatively evenly distributed across topics. Third, the explanatory power of the statistical model is small. Theoretically, it suggests that emotion could not adequately explain or predict the change in the level of participation. Empirically, the proposed model only considers the linear relationship between variables. Since a high level of anxiety can also inhibit action, as suggested by studies on anxiety disorder, the relationship between emotions and participation may resemble a U-shaped curve. Finally, by only studying participation, this study cannot answer the question of what makes non-participants participate.

In general, our findings suggest that certain emotions are beneficial in promoting participation in deliberation, providing evidence somewhat different from the conventional belief that emotions can hamper reason and articulation. Anxiety, the least prevalent type of emotion expressed on the platform, increases the level of engagement, and could potentially contribute to a well-informed, healthy participation. However, anger dominates issue discussion across topics, and yet does not affect the level of participation. This study contributes to a better knowledge about the roles of different types of emotions in e-participation and could potentially assist practitioners and decision makers to manage public emotions in a constructive manner that mobilises citizens to engage in public issues. 


\section{References}

Balahur, A., \& Turchi, M. (2014). Comparative experiments using supervised learning and machine translation for multilingual sentiment analysis. Computer Speech \& Language, 28(1), 56-75.

Barlow, D. H. (2000). Unraveling the mysteries of anxiety and its disorders from the perspective of emotion theory. American psychologist, 55(11), 1247.

Berger, J., \& Milkman, K. L. (2012). What makes online content viral? Journal of marketing research, 49(2), 192-205.

Blei, D. M., Ng, A. Y., \& Jordan, M. I. (2003). Latent dirichlet allocation. Journal of machine Learning research, 3(Jan), 993-1022.

Brader, T. (2005). Striking a responsive chord: How political ads motivate and persuade voters by appealing to emotions. American Journal of Political Science, 49(2), 388-405.

Campbell, D. E. (2006). Why we vote: How schools and communities shape our civic life. Princeton NJ: Princeton University Press.

Carpini, M. X. D., Cook, F. L., \& Jacobs, L. R. (2004). Public deliberation, discursive participation, and citizen engagement: A review of the empirical literature. Annu. Rev. Polit. Sci., 7, 315-344.

Chen, X., Acosta, S., \& Barry, A. E. (2016). Evaluating the accuracy of google translate for diabetes education material. JMIR Diabetes, 1(1), e3.

Damasio, A. R., \& Damasio, H. (1994). Cortical systems for retrieval of concrete knowledge: The convergence zone framework. In C. Koch \& J. Davis (Eds.), Large-scale neuronal theories of the brain (p. 23-60). MIT Press.

Dillard, J., \& Shen, L. (2007). Self-report measures of discrete emotions. In Handbook of research on electronic surveys and measurements (pp. 330-333). IGI Global.

Feldman Barrett, L., \& Russell, J. A. (1998). Independence and bipolarity in the structure of current affect. Journal of personality and social psychology, 74(4), 967.

Fox, C. (1989). A stop list for general text. In Acm sigir forum (Vol. 24, pp. 19-21).

Glaser, J., \& Salovey, P. (1998). Affect in electoral politics. Personality and social psychology review, 2(3), 156-172.

Groves, M., \& Mundt, K. (2015). Friend or foe? google translate in language for academic purposes. English for Specific Purposes, 37, 112-121.

Gruszczynski, M. W., Balzer, A., Jacobs, C. M., Smith, K. B., \& Hibbing, J. R. (2013). The physiology of political participation. Political Behavior, 35(1), 135-152.

Haidt, J. (2012). The righteous mind: Why good people are divided by politics and religion. NewYork: Pantheon.

Hanoch, Y. (2002). "neither an angel nor an ant": Emotion as an aid to bounded rationality. Journal of Economic Psychology, 23(1), 1-25. 
Heilman, K. (1997). The neurobiology of emotional experience. The neuropsychiatry of limbic and subcortical disorders, 133-142.

Hume, D. (1978). A treatise of human nature. Oxford, UK: Clarendon Press.

Jasper, J. M. (1998). The emotions of protest: Affective and reactive emotions in and around social movements. In Sociological forum (Vol. 13, pp. 397-424).

Kahn, J. H., Tobin, R. M., Massey, A. E., \& Anderson, J. A. (2007). Measuring emotional expression with the linguistic inquiry and word count. The American journal of psychology, 263-286.

Kleinginna, P. R., \& Kleinginna, A. M. (1981). A categorized list of emotion definitions, with suggestions for a consensual definition. Motivation and emotion, 5(4), 345-379.

Kuhlen, R. (1977). Experimentelle morphologie in der informationswissenschaft. München : Verlag Dokumentation.

Ladd, J. M., \& Lenz, G. S. (2008). Reassessing the role of anxiety in vote choice. Political Psychology, 29(2), 275-296.

Lerner, J. S., \& Keltner, D. (2000). Beyond valence: Toward a model of emotionspecific influences on judgement and choice. Cognition \& emotion, 14(4), 473-493.

Lerner, J. S., \& Keltner, D. (2001). Fear, anger, and risk. Journal of personality and social psychology, 81(1), 146-159.

Li, H., Graesser, A. C., \& Cai, Z. (2014). Comparison of google translation with human translation. In Flairs conference (pp. 190-195).

MacKuen, M., Wolak, J., Keele, L., \& Marcus, G. E. (2010). Civic engagements: Resolute partisanship or reflective deliberation. American Journal of Political Science, 54(2), 440-458.

Marcus, G. E., Neuman, W. R., \& MacKuen, M. (2000). Affective intelligence and political judgment. Chicago and Lonond, UK: University of Chicago Press.

Matthes, J., Rios Morrison, K., \& Schemer, C. (2010). A spiral of silence for some: Attitude certainty and the expression of political minority opinions. Communication Research, 37(6), 774-800.

Moy, P., Domke, D., \& Stamm, K. (2001). The spiral of silence and public opinion on affirmative action. Journalism \& Mass Communication Quarterly, 78(1), 7-25.

Mutz, D. C. (2002). The consequences of cross-cutting networks for political participation. American Journal of Political Science, 838-855.

Newman, D., Asuncion, A., Smyth, P., \& Welling, M. (2009). Distributed algorithms for topic models. Journal of Machine Learning Research, 10(Aug), 1801-1828.

Nir, L. (2005). Ambivalent social networks and their consequences for participation. International Journal of Public Opinion Research, 17(4), 422-442.

Noelle-Neumann, E. (1974). The spiral of silence a theory of public opinion. Journal of communication, 24(2), 43-51. 
Noelle-Neumann, E. (1979). Public opinion and the classical tradition: A reevaluation. Public Opinion Quarterly, 43(2), 143-156.

Pennebaker, J. W., Boyd, R. L., Jordan, K., \& Blackburn, K. (2015). The development and psychometric properties of LIWC2015.

Russell, J. A. (2003). Core affect and the psychological construction of emotion. Psychological review, 110(1), 145.

Ryan, T. J. (2017). No compromise: Political consequences of moralized attitudes. American Journal of Political Science, 61(2), 409-423.

Simons, J. J., \& Green, M. C. (2018). Divisive topics as social threats. Communication Research, 45(2), 165187.

Spezio, M. L., \& Adolphs, R. (2007). Emotional processing and political judgment: Toward integrating political psychology and decision neuroscience. The affect effect: Dynamics of emotion in political thinking and behavior, 71-95.

Tausczik, Y. R., \& Pennebaker, J. W. (2010). The psychological meaning of words: Liwc and computerized text analysis methods. Journal of language and social psychology, 29(1), 24-54.

Tiedens, L. Z. (2001). Anger and advancement versus sadness and subjugation: the effect of negative emotion expressions on social status conferral. Journal of personality and social psychology, 80(1), 86.

Valentino, N. A., Brader, T., Groenendyk, E. W., Gregorowicz, K., \& Hutchings, V. L. (2011). Election night's alright for fighting: The role of emotions in political participation. The Journal of Politics, 73(1), 156-170.

Valentino, N. A., Hutchings, V. L., Banks, A. J., \& Davis, A. K. (2008). Is a worried citizen a good citizen? emotions, political information seeking, and learning via the internet. Political Psychology, 29(2), 247273.

Verba, S., Schlozman, K. L., \& Brady, H. E. (1995). Voice and equality: Civic voluntarism in american politics. London, UK: Harvard University Press.

Weber, C. (2013). Emotions, campaigns, and political participation. Political Research Quarterly, 66(2), 414428.

Yao, L., Mimno, D., \& McCallum, A. (2009). Efficient methods for topic model inference on streaming document collections. In Proceedings of the 15th acm sigkdd international conference on knowledge discovery and data mining (pp. 937-946).

\section{About the Authors}

\section{Thomas J. Lampoltshammer}

Thomas J. Lampoltshammer is Assistant Professor for ICT and Governance, as well as the Deputy Head of the Centre for E-Governance at the Department for E-Governance and Administration at Danube University Krems. His current research focuses on the effects of ICT application in a connected society and the effects on a data-driven society. 


\section{Qinfeng Zhu}

Qinfeng Zhu is an Assistant Professor at the Department of Media Studies and Journalism at the University of Groningen. Her research examines how emerging technologies reconfigure citizens' social relations and information environments, its implications for citizens' political and civic (dis)engagement and the shape of democracy at large.

\section{Peter Parycek}

Peter Parycek is Full Professor for E-Governance, Head of the Department for E-Governance and Administration at Danube University Krems and Head of the Competence Centre Public IT at Fraunhofer Fokus Berlin, funded by the Ministry of Interior. In August 2018 he has become a member of the Digital Council to advise the German government on strategic questions of digital transformation. 